\title{
Recovery of materials and fresh water supply using renewable energy
}

\begin{abstract}
Growing population, progressively increasing lifestyle and related demand creates pressure on the huge but finite global resources. The water-energy-food nexus implicitly includes also materials both fuels and non-fuels. Besides water, food and energy demand, the demand for materials is in fact also steadily growing. Pressure on materials resources is often directly translated into pressure on land use, massively utilized already for food and energy production, fresh water, fuels supply, etc. New technologies will make our life even easier and more comfortable but inevitably the pressure on resources will rise also in scenarios with high renewable energy sources (RES) penetration. Direct utilization of RES at the harvesting locations for the production of materials could be an option also to avoid huge energy transmission and storage infrastructures, as well as benefit of overall higher efficiency. One way can be the use of RES to extract brines and salts from sea water. The produced materials could then be stored and transported to land for further processing possibly using RES sources as well.

Potentially the impact on land could be negligible or even positive, since deserts, dry inhabited sea shores or islands, unsuitable for agriculture, or salt lakes could be utilized and water generated at the same time. RES harvesting potential in such areas is often huge while possibility to deliver the energy to dense populated areas is limited.

In this paper, the potential for recovery of materials and fresh water from sea water using RES is investigated. The conclusions are indicating concrete possibilities for sustainable materials production in particular for calcium, potassium and magnesium for which the European Union (EU) supplies dependency is $100 \%$. The potential to generate significant amounts of fresh water in remote, often dry areas is huge as well. The technology could be exploited by all countries with sea access.
\end{abstract}

Keywords: raw materials, fresh water supply, renewable energy, sea water
Volume 2 Issue I - 2018

\section{Blagoeva D, Debarberis L}

European Commission, Netherlands

Correspondence: Blagoeva D, European Commission, Netherlands, Email Darina.BLAGOEVA@ec.europa.eu

Received: April 04, 2017| Published: January 17, 2018

\section{Introduction}

World population is constantly growing and at the same time the lifestyle is increasing progressively. The growth process requires intense exploitation of known resources as well as more and more new resources to be made available. Such growing demand creates pressure on the huge but finite available global resources. Water, food and energy demand is growing proportionally and are interrelated in a complex way, the so-called water-energy-food nexus. ${ }^{1}$ Similarly the demand for materials, inevitably related to water, energy and food supply is steadily increasing as well and they are implicitly part of the nexus. Adequate supply is required in order to secure our present and to sustain the growth satisfying the increasing needs. The pressure on resources is often directly translated on pressure on the land use. Land is massively utilized for food production, fresh water supply, fuels supply, energy production as well as extraction of materials. Already at this stage there are discussions on possible competition between the various activities with regard to land use; the case of bio-masses just to mention the most evident case..$^{2-4}$ New technologies will make our life even easier and more comfortable but inevitably they will put more pressure on different resources. For example the large deployment of batteries has already an impact on the supply of lithium worldwide and the utilization of magnesium ion batteries in the near future may pose the same issue. ${ }^{5}$ Another example is the supply of rare earth elements critical for the development of renewable energy and other smart technologies. ${ }^{6-8}$ From the EU perspective, restricting to energy, both the supply of fuels and raw materials are mainly depending on imports from outside the EU. This is weakening somehow the future security of supply and it is posing question for the long-term strategy to follow. ${ }^{9}$

Besides land use constrains, coming back to food production, even if the EU has a strong agricultural infrastructure, it also depends heavily on import of fertilizers - again a sort of raw material. It is important to develop more renewable resources, both energy and materials, coping with the future growing demands while possibly reducing pressure on land use. One possibility that has always been considered is to exploit more effectively the seas, salt lakes, underwater salt waters and oceans. Sea water is known to contain in fact many different elements which can be employed for the food chain as well as the raw material supply. Besides sodium, calcium, potassium, magnesium, lithium and titanium, molybdenum and not to mention uranium and thorium can be obtainable form sea water. Important natural resources of this type are so called brines deposits, where generally sea and ground water has been evaporated by contact with hot geothermal or volcanic rocks and consequently the salts concentrated..$^{10}$ Brines may have significantly different composition depending on the origin of the water and the nature of the rocks and other factors. Elements concentrations can be significantly enriched as well when compared to sea water. Huge brines deposits exist worldwide and they will be further exploited in few decades but they are again finite resources outside the EU. 
The issue is that the elements mentioned above are very much diluted and conventional processes often fail to be competitive. Just the mere energy required to evaporate away part of the water to concentrate the salt is often a killing factor. Historically, however, we have extracted salt from sea water in an acceptable way using evaporation process in the so called saline. The process relies on huge surfaces on land, ponds, where sea water is pumped in and let evaporated by nature; sun, wind as well as time and temperature. The process is rather slow and requires extensive surfaces. However, 'mining' different elements from sea water directly could be done at larger scale directly on deserted islands not suitable for agricultural or other purposes or even off shore (with floating structures).

\section{What exactly sea water contains?}

A very well-known fact is that the sea water contains sodium,

Table I Common elements contained in sea water being also the most abundant element there. In addition, there are considerable amounts of other valuable elements. A list of the most common elements contained in sea water together with their relevant applications is given in Table 1 below. The materials major suppliers and the EU net import dependency are also presented in the Table.

With few exceptions, data from USGS, 2016 ${ }^{11}$ were used to determine the main supplier shares. Calcium data on shares refers to lime production. USGS $2011^{12}$ is used to calculate the supplier shares for boron; the latest years USA data were not reported and USA is one of the major suppliers. Data for titanium refers to titanium and titanium dioxide production. Data for potassium refers to potash. The EU import dependency on calcium is stated to be $100 \%$; although France has the ability to produce calcium metal, it does not currently use the facilities to produce it. ${ }^{13}$ The EU import dependency on the other materials in Table 1 is obtained from..$^{14,22}$

\begin{tabular}{|c|c|c|c|c|}
\hline Material & $\begin{array}{l}\text { Content per Mt } \\
\text { sea water }\end{array}$ & Main suppliers (shares) & $\begin{array}{l}\text { EU import } \\
\text { dependency }\end{array}$ & Relevant applications \\
\hline Magnesium & 1290 tones & China (88\%), Others (I2\%) & $100 \%$ & $\begin{array}{l}\text { Aluminium packaging, vehicles, aluminium alloy } \\
\text { construction elements, steel desulphurization } \\
\text { agents, production of titanium metal, electronic } \\
\text { devices, batteries (at development stage). }\end{array}$ \\
\hline Sulphur & 904 tones & $\begin{array}{l}\text { China (15\%), USA (14\%), } \\
\text { Russia(10\%), Others (61\%), }\end{array}$ & $0 \%$ & $\begin{array}{l}\text { Fertilizer industry, manufacturing non-ferrous } \\
\text { metals, pigments, fibres, pharmaceuticals, } \\
\text { pesticides, cosmetics, rubber, vulcanization, } \\
\text { water treatment, steel pickling, etc. }\end{array}$ \\
\hline Potassium & 400 tonnes & $\begin{array}{l}\text { Canada (28\%), Russia (I } 9 \%) \text {, } \\
\text { Belarus (17\%), China (I I\%), } \\
\text { Others }(25 \%)\end{array}$ & $23 \%$ & $\begin{array}{l}\text { Agriculture (fertilizer), production of explosives } \\
\text { glass. }\end{array}$ \\
\hline Calcium & 400 tones & China $(66 \%)$, Others (34\%) & $100 \%$ & $\begin{array}{l}\text { Alloying agent in the production of aluminium, } \\
\text { beryllium, copper, lead, and magnesium alloys; } \\
\text { deoxidizer, desulfurizer, or decarbonizer for } \\
\text { various ferrous and non-ferrous alloys; reducing } \\
\text { agent in the extraction of uranium, zirconium, } \\
\text { thorium; cements and mortars production for } \\
\text { construction; food industry. }\end{array}$ \\
\hline Boron & 4.5 tones & $\begin{array}{l}\text { Turkey (39\%), USA ( } 24 \%) \text {, } \\
\text { Argentina (14\%), Chile } \\
\text { (10\%), Others (13\%) }\end{array}$ & $98 \%$ & $\begin{array}{l}\text { Production of heat resistant glass, including } \\
\text { fibreglass insulation \& textile; production of } \\
\text { ceramics; pharmaceuticals \& personal care } \\
\text { products; agriculture; nuclear reactors. }\end{array}$ \\
\hline Strontium & 8.1 tones & $\begin{array}{l}\text { China }(47 \%) \text {, Spain }(28 \%) \text {, } \\
\text { Mexico }(22 \%) \text {, Others (3\%) }\end{array}$ & No data found & $\begin{array}{l}\text { Pyrotechnics; used as carbonate in special glass } \\
\text { for television screens and visual display units; } \\
\text { used to generate electric current in space } \\
\text { vehicles, remote weather stations and navigation } \\
\text { buoys; several different forms are used in } \\
\text { medicine. }\end{array}$ \\
\hline Lithium & I 70 kilograms & $\begin{array}{l}\text { Australia (4I\%), Chile (36\%), } \\
\text { Others (23\%) }\end{array}$ & $75 \%$ & $\begin{array}{l}\text { Batteries; ceramics / glass production; lubricates; } \\
\text { synthetic rubbers \& plastics; gas \& air treatment; } \\
\text { continuous casting; pharmaceuticals; aluminium } \\
\text { smelting. }\end{array}$ \\
\hline Uranium & 3 kilograms & $\begin{array}{l}\text { Kazakhstan, Canada, } \\
\text { Australia, Others }\end{array}$ & $>40 \%$ & $\begin{array}{l}\text { Fuel for nuclear reactors; production of } \\
\text { synthetic trans-uranium elements; military } \\
\text { usages - to power nuclear submarines and in } \\
\text { nuclear weapons. }\end{array}$ \\
\hline $\begin{array}{l}\text { Titanium, } \\
\text { manganese, } \\
\text { vanadium, } \\
\text { molybdenum }\end{array}$ & I, 2,2 \& I0 kilograms & $\begin{array}{l}\text { China (47\%), Russia (25\%), } \\
\text { Japan (18\%), Others (1 I\%) }\end{array}$ & & $\begin{array}{l}\text { Titanium: alloying agent in many metals - } \\
\text { aluminium, molybdenum and iron; surgical } \\
\text { applications - especially hip joints \& tooth } \\
\text { implants; paints, plastics \& enamels; sunscreens. }\end{array}$ \\
\hline
\end{tabular}


Table Continued.

\begin{tabular}{|c|c|c|c|c|}
\hline Material & $\begin{array}{l}\text { Content per Mt } \\
\text { sea water }\end{array}$ & Main suppliers (shares) & $\begin{array}{l}\text { EU import } \\
\text { dependency }\end{array}$ & Relevant applications \\
\hline & & $\begin{array}{l}\text { South Africa (34\%), China } \\
\text { (17\%), Australia (16\%), } \\
\text { Others (33\%) }\end{array}$ & & $\begin{array}{l}\text { Manganese: steel production; additive to many } \\
\text { aluminium alloys; used in dry-cell batteries and } \\
\text { other fields of the chemical industry. }\end{array}$ \\
\hline & & $\begin{array}{l}\text { China (53\%), South Africa } \\
(24 \%) \text {, Russia (19\%), Others } \\
(4 \%)\end{array}$ & $\begin{array}{l}100 \%, 90 \%, 100 \% \\
100 \%\end{array}$ & $\begin{array}{l}\text { Vanadium: used as additive in alloy steels; } \\
\text { alloying element in titanium alloys; catalysts } \\
\text { for chemicals; pigment for ceramics \& glass; in } \\
\text { producing superconducting magnets. }\end{array}$ \\
\hline & & $\begin{array}{l}\text { China }(38 \%), \text { USA }(21 \%), \\
\text { Chile (18\%), Others }(23 \%)\end{array}$ & & $\begin{array}{l}\text { Molybdenum: alloying element in steel, cast iron } \\
\text { \& super alloys for a wide range of applications; } \\
\text { lubricant additive; catalysts for petroleum } \\
\text { industry; inks for circuit boards, pigments and } \\
\text { electrodes. }\end{array}$ \\
\hline
\end{tabular}

As can be seen from Table 1, the EU is strongly dependent on third countries for the supply of most of the materials found in sea water, used in a broad range of applications. The import dependency varies between $75 \%$ and $100 \%$ which might create possibly a problem of securing the supply of these materials in the future.

\section{Sea water versus brines}

As mentioned before, the so-called brines occurring in different location on earth as typical natural resources for materials. Huge brines deposits exist worldwide and they will be further exploited in few decades but they are again finite resources outside the EU. Such deposits may have significantly different composition depending of the origin and other factors (e.g. marine, non-marine, hybrid, alkaline brines etc.). Saltwater isolated in salt lakes has evaporated in long geological eras mainly due to volcanic/geothermal source or surface evaporation, leaving concentrated brines or even solid deposits. Nonmarine brines are originated by, for example, rivers depositing again along geological eras elements washed away from rocks. The contact with particular rocks and the quality of inflow rain water is also playing a role in the brine formation.

Combinations of factors are also widely observed in nature making the composition of brines very diverse and being suitable for specific exploitation. For example, the lithium-rich brines of Salar de Uyuni in the Bolivian Altiplano-one of the largest salt pan on Earthcontain lithium at concentrations in the order of $500 \mathrm{ppm}$ or $500 \mathrm{~g} / \mathrm{t}$ (concentrations are ranging from 80ppm up to $1500 \mathrm{ppm}$ depending on location). Even higher concentration are found at specific locations, while the lower level which is still commercially interesting for exploitation is about 20ppm (USA). By comparison, the enrichment in lithium compared to sea water is approximately of a factor 120 ; which in terms means that a lot of sea water needs to be evaporated to obtain high concentrated brines economically viable for further exploitation

The situation is almost reversed when we compare the figures for magnesium; its concentration in sea water, 1290ppm, is far higher than the one found in most brines. Whatever the target element is, the concentration process would generate huge amount of valuable products like it happens with brines. In fact, coming back to brine exploitation, lithium is often a by-product while potassium is one of the main products. In any case, as mentioned before, huge amounts of fresh water could be co-produced in parallel which could be utilized in dry areas for many purposes e.g. human settlement, agriculture, tourism etc.

\section{Energy and power requirements}

Yes, there are plenty of valuable elements in sea water but one basic question is of course how to separate or at least to concentrate the salt from the huge amount of water. The energy required to concentrate sea water by evaporation can be estimated as well as the power requirements depending on the processing time requirements. Renewable energy is in particular evaluated for its potential to recover valuable elements from sea water. Renewable energies especially in the form of solar and wind are often also available in regions with limited or no-access to energy transmission and distribution grids. This is particularly true for the off-shore case or the case of remote non habited islands. In many cases, the potential harvesting of renewable energy is associated in the best case with such huge grid investments that are making the projects impossible. Often the connection to a grid is not at all technically feasible. The utilization of renewable energy directly on those locations for the production of raw materials may be more economically attractive for the above mentioned cases. The produced materials could be then piled and carried on-shore by sea vessels.

Harvesting and utilizing RES at the source location, avoiding power transmission infrastructure and reducing energy conversion steps will enhance overall efficiency of the whole process. This has to be kept in mind since the energy requirement remains one critical element which often puts the process out of business. For example, a few years ago it was in fact discussed the possibility to extract fissile fuels, like uranium and thorium from sea water to feed nuclear reactors. ${ }^{15}$ The process was based on pumping sea water through a membrane. The required energy turned to be too high even in comparison to the energy which could be obtained from the recovered fissile fuel, making the whole process not sustainable. Other technologies are at development stage, like absorption mats which may be less energy demanding ${ }^{16}$ or the so called Metal-organic Frameworks. ${ }^{17}$ In the following, with a view of RES utilization, we will focus on water evaporation as the main process to concentrate salts. We assume here to utilize direct solar thermal energy for the main evaporation process and other renewable for the required pumping of the sea water and brine. The concentration of the salt by evaporation of the water requires a lot of energy. Assuming salt water temperature of approximately $15^{\circ} \mathrm{C}$, the minimum energy required to warm up and then evaporate 1 tone of water can be estimated as $0,73 \mathrm{MWh} /$ tone.

As we know solar radiation at a good solar location in the summer months may yield at least $4 \mathrm{KWh} /$ day $/ \mathrm{m}^{2}$ of heat considering approximately 4 hours equivalent of peak radiation. This means that, if 
we consider $1 \mathrm{~km}^{2}$ a total energy of $4000 \mathrm{MWh} /$ day in the form of heat is available. In turns, potentially slightly more than 5000 tones per day of water could be evaporated. Assuming good radiation condition and $50 \%$ of the year operation schedule (like summer seasons in the Mediterranean areas), we could ideally evaporate approximately 1Megatonne/year of water utilizing the reference $1 \mathrm{~km}^{2}$ of solar thermal energy. As a result we would concentrate solutions containing more than 1000 tones of magnesium, 400tonnes of potassium and calcium and other elements (Table 1).

There are also other power requirements to be evaluated; mainly the power required to pump the huge amount of water from the intake through the whole process. The power required depends mainly on the elevations to which the water needs to be pumped as well as other factors such as water treatment, depleted water separation requirements, etc. Power in the range of the tens of MWe is required as a minimum to feed $1 \mathrm{~km}^{2}$ of installation. To obtain the power in remote areas, photovoltaic or wind installations could be employed, requiring additional surface to be placed; such surface is anyhow far smaller when compared to the overall surface required. Other options to generate power could be deployment of geothermal sources, heat pumps, etc.

\section{Discussion}

In any case, to exploit seas and oceans, sea water needs to be segregated and evaporated. Different strategies to recover the different elements can be followed then. The concentration could be obtained by evaporation of the water like it was done and still done in many places in Salinas. Like obtained in Salinas, renewable energy is the most promising option-it only needs to be optimized to compensate for otherwise long evaporation times. As calculated in the previous sections, utilizing $1 \mathrm{~km}^{2}$ of surface, in a Mediterranean region of the EU we could potentially evaporate approximately 1 Megatonne of sea water using solar thermal energy. In order to minimize the impact on land use, ideally floating installations on a salt lake or making use of land unsuitable for agriculture like lake and seas shore, desert islands or areas are desirable. The result of the yearly operation would then be the production of concentrated brines offering real possibility to extract valuable material. If we conservatively assume a recovery percentage of approximately $50 \%$ for the various elements we could estimate to recover annually the amounts given in Table 2 .

Deploying more units, or better utilizing a larger field, results become of interest for large scale supply. A single desert island or floating structure in the lower Mediterranean region of the EU with a surface of $1000 \mathrm{~km}^{2}(\approx 30 \times 33 \mathrm{~km})$ would make available 500.000 tones of magnesium, 200 thousand tones of potassium and 85 tonnes of lithium as by-product. The mentioned amount of magnesium is huge considering that the world's production is in the range of a Megatonne. ${ }^{18}$ Lithium amount is rather low; by comparison, Australia and Chile were the biggest producers of lithium in 2015 with approximately 12-13 thousand tones each. ${ }^{11}$ The advent of Magnesium-ion batteries in the near future will be a key development. ${ }^{19}$ The possibility to extract Magnesium from sea water attracts the attention also of big countries such as USA. ${ }^{20}$ Currently research is ongoing on developing energy effective techniques for Magnesium recovery from sea water. Additional RES driven or chemical exchange processes may be developed for purification and metal reduction whenever required.

The proposed installation will be fully renewable, and besides raw materials, will be able to make available huge mass supply of fresh water which may be of high value for human use and further exploitation of agriculture, especially in remote dry areas.

Table 2 Materials, besides sodium chloride, theoretically recoverable per year per $\mathrm{km}^{2}$ of surface

\begin{tabular}{ll}
\hline Material & Annual estimated production \\
\hline Magnesium & 500 tones \\
Potassium & 200 tones \\
Calcium & 200 tones \\
Strontium & 4 tones \\
Boron & 2,3 tones \\
Lithium & 85 kilograms \\
Molybdenum & 5 kilograms \\
Uranium & I,5 kilograms \\
Manganese & I kilogram \\
Vanadium & I kilogram \\
Titanium & 0,5 kilograms \\
\hline
\end{tabular}

It is worth to be noted that the idea could be exploited by all countries with direct or indirect access to the sea. Of course when relying on renewable energy based on solar for the evaporation, the latitude may be critical for the productivity index for installations relying on solar radiation. Utilization of renewable wind energy offshore might be more appropriate for higher latitudes.

It should be recognized that RES can be deployed in a way not competing with energy production. On the contrary, it can be better deployed in areas near the coastline or inside land but with easy connection to the sea coastline where the access to a suitable energy infrastructure is difficult and of course where RES are abundant. It is in fact unlikely that RES will be harvested for energy purposes due to the high costs of laying additional energy grid infrastructures. A rough estimation of the huge potential available can be than obtained by evaluating the surface areas of such regions.

A simple approximation can be done for the EU, just considering the case of solar RES. It will be a conservative estimation, but indicating the order of magnitude of the potential which, as mentioned before, will ever be hardly exploited for energy production anyhow. As a proxy of the energy infrastructure we can consider the existing transmission-distribution electrical grid. Areas far from the available energy infrastructure, often scarcely inhabited as well, are taken into account for the evaluation. Focusing on solar RES, we can then further limit the evaluation by restricting the latitude range between $42^{\circ} \mathrm{N}$ to $35^{\circ} \mathrm{N}$ to account for the higher and longer solar exposure across the year.

A fast estimation indicates that it is easy to point at a suitable surface in the range of at least $2000 \mathrm{~km}^{2}$. This means a potential in the range of approximately 1 Megatonne per year for magnesium, approaching the global supply figure of the worlds, and far more than the EU consumption. In fact, the EU supply, which is approximately 170 thousand tones ${ }^{21}$ per year, can be obtained exploiting about less than $340 \mathrm{~km}^{2}$. These estimations should be considered rather conservative. In fact just for comparison the small islands of Kythira and Karpathos in Greece in a suitable climatic region are together larger than $700 \mathrm{~km}^{2}$, while inhabited by just 11.300 inhabitants (with 
population declining as in many of the smaller Aegean islands). For a more precise estimation a more sophisticated analysis is necessary, for example applying geographic information system (GIS) software. This will be the topic of a dedicated following study. The same can be done considering other RES sources and different climatic areas.

As an additional benefit, more than $60 \%$ of the calcium and $30 \%$ of the potassium, which EU imports (in the form of calcium carbonate and potash) from non-EU countries ${ }^{22}$ can be harvested from the same surface of $2000 \mathrm{~km}^{2}$; to compensate for the whole EU import of these two raw materials, surfaces of roughly $3500 \mathrm{~km}^{2}$ and $6500 \mathrm{~km}^{2}$ respectively would be required. Although non-critical for the EU economy, these two materials are feeding stock for important sectors, such as agriculture (fertilizers), chemicals, construction, production of glass, paper, plastics, etc.

A simplified sketch of the system layout is presented in Figure 1. One more obvious advantage of such concept is obtaining significant amount of salt being predominantly used as a feedstock for the production of industrial chemicals. The demand for salt has upward trend and new possibilities are currently explored in the EU, e.g. Akzo Nobel's Specialty Chemicals business is opting to extent by $25 \%$ its production of high-purity salt in the Netherlands, following extension of its facility in Denmark. A new joint venture has also been recently established in Spain. ${ }^{23}$ Currently, the EU possesses only $18 \%$ share in the global production with Germany being the major EU producer, while China and the United States are the largest salt producers, accounting together for around $37 \%$ of the global salt production. ${ }^{24,25}$ The EU is also one of the biggest salt importers globally: in 2016 the EU imported $\$ 920.3$ million worth of salt. ${ }^{26}$

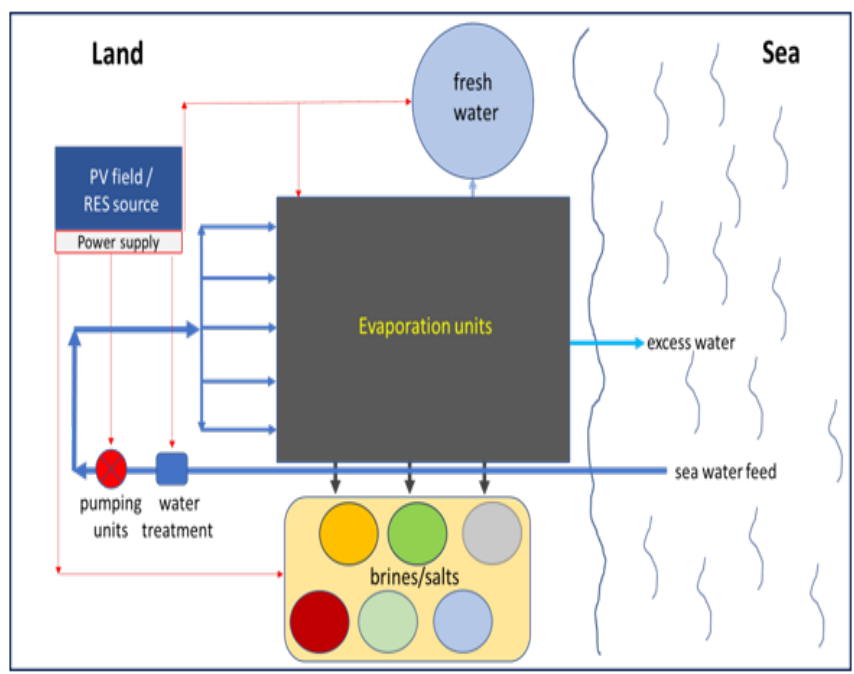

Figure I Schematic system layout for the case of solar thermal and PV.

\section{Conclusion}

Sea water contains valuable materials which are important for different industrial sectors such as energy, transport, agriculture, metals production, etc. The EU reliance on these materials is very high; in most cases above $75 \%$. The concentration levels of these materials in sea water are rather low but almost constant worldwide. Concentration process to obtain brines via evaporation employing renewable energies can be the starting point for exploitation. Salt production could be of course just one more benefit of such projects. Benefits would also include reduced need of power transmission infrastructure by harvesting and utilizing RES at the source location and as much as possible exploiting directly thermal energy, assuring thus increased overall efficiency.

Just as an indication, a a significant amount of magnesium, sulphur, potassium and calcium plus several other elements in smaller quantities can be retrieved from an area of only $1 \mathrm{~km}^{2}$. For the production of magnesium necessary to satisfy the current EU demand, a surface area of approximately $340 \mathrm{~km}^{2}$ would be sufficient. An area of approximately $2000 \mathrm{~km}^{2}$, estimated to be easily available just in the EU could deliver the current global magnesium production in the range of 1Megatonne. To be noted that magnesium, on which we depend $100 \%$ from non-EU suppliers, is an attractive candidate also for the development of future rechargeable magnesium-ion battery technology. As an additional benefit, the import reliance on other raw materials such as potassium, sulphur, calcium and salt can be substantially reduced.

Potentially the impact on land could be negligible since dry inhabited islands could be utilized at first place. Possible floating concepts could be developed as well, for example on salt lakes. Additionally, the process could create mass supply of fresh water in remote dry areas for further exploitation of agriculture, positively impacting the water-energy-food nexus. It should be noted that the concept could be exploited easily by countries with access to sea. It can have a particular interest for the EU due to its huge import dependency on raw materials, creating possibly a problem of security of supply in the future.

\section{Acknowledgements}

None.

\section{Conflict of interest}

The author declares no conflict of interest.

\section{References}

1. IRENA. Renewable Energy in the Water, Energy \& Food Nexus. 2015.

2. Witcover J. Policy options to address global land use change from biofuels change from biofuels. Energy Policy. 2013;56:63-74.

3. Bryngelsson DK. Why large-scale bioenergy production on marginal land is unfeasible: A conceptual partial equilibrium analysis. Energy Policy. 2013;55:454-466.

4. Kauffman NS. The trade-off between bioenergy and emissions with land constraints. Energy Policy. 2013;54:300-310.

5. Miedema JH. Lithium availability in the EU27 for battery-driven vehicles: The impact of recycling and substitution on the confrontation between supply and demand until 2050. Resources Policy. 2013;38(2):204-211.

6. Golev A. Rare earths supply chains: Current status, constraints and opportunities. Resources Policy. 2014;41:52-59.

7. Stegen KS. Heavy rare earths, permanent magnets, and renewable energies: An imminent crisis. Energy Policy. 2015;79:1-8.

8. Habib K. Exploring rare earths supply constraints for the emerging clean energy technologies and the role of recycling. Journal of Cleaner Production. 2014;84(1):348-359.

9. Kim J. Critical and precious materials consumption and requirement in wind energy system in the EU 27. Applied Energy. 2015;139(1):327334. 
10. Kesler SE. Global lithium resources: Relative importance of pegmatite brine and other deposits. Ore Geology Reviews. 2012;48:55-69.

11. Mineral commodity summaries 2016. USA Geological Survey, 202 p.

12. Mineral commodity summaries 2011. USA Geological Survey, 198 p.

13. Minor Metal Trade Association Website.

14. Sievers H. European dependence on and concentration tendencies of the material production. Polinares. 2012:11.

15. Ugo Bardi. Extracting Minerals from Seawater: An Energy Analysis. Sustainability. 2010;2(4):980-992.

16. Nor Azillah Fatimah O. A review of Uranium Extraction from Seawater: Recent International R\&D. Iaea Inis collection. 2012.

17. Mike Orcutt. Novel material shows promise for extracting uranium from sea water. MIT Technology Review. 2013.

18. Primary magnesium production worldwide from 2010 to 2017. Statista.

19. Yunpeng Gu. Rechargeable magnesium-ion battery based on a TiSe2cathode with d-p orbital hybridized electronic structure. Scientific Reports. $2015 ; 5: 12486$.
20. Mineral Commodity Summaries, Magnesium Metal. US Geological Survey.

21. BIO by Deloitte. Study on Data for a Raw Material System Analysis: Roadmap and Test of the Fully Operational MSA for Raw Materials. Prepared for the European Commission, Dg Grow. 2013.

22. Study on the review of the list of Critical Raw Materials. European Commission, 2017.

23. AkzoNobel. AkzoNobel to expand high-purity salt production in the Netherlands; 2017.

24. The World's Top Salt Producing Countries. Worldatlas, Economics.

25. Major countries in salt production worldwide from 2011 to 2016. Statista.

26. Worlds, richest countries statistics. 